\title{
Effects of long-acting and short-acting $\beta$-agonists on methacholine dose-response curves in asthmatics
}

\author{
A.G. Wong, A.D. O'Shaughnessy, C.M. Walker, M.R. Sears
}

\begin{abstract}
Effects of long-acting and short-acting $\beta$-agonists on methacholine dose-response curves in asthmatics. A.G. Wong, A.D. O'Shaughnessy, C.M. Walker, M.R. Sears. @ERS Journals Ltd 1997.

ABSTRACT: Regular use of short-acting $\beta$-agonists may decrease control of asthma and increase airway responsiveness to bronchoconstrictor stimuli. The aim of this study was to determine the effects of regular treatment with the long-acting $\beta$-agonist, salmeterol, on the methacholine dose-response curve (DRC) in mild-tomoderate asthmatics.

Changes in methacholine airway responsiveness were measured in 14 stable adult asthmatics, randomized in a double-blind, three-way cross-over design to receive salmeterol $50 \mu \mathrm{g}$, salbutamol $200 \mu \mathrm{g}$ or placebo, each twice daily for 4 days. Two baseline methacholine DRC, were performed, one without premedication and one following a single dose of $200 \mu \mathrm{g}$ salbutamol. Following 4 days of regular treatment, methacholine DRC to plateau were carried out commencing 15 min after the final dose of trial medication.

There were no significant differences in mean baseline forced expiratory volume in one second (FEV1) between treatments. Four days treatment with salmeterol and salbutamol shifted the DRC to the right, but salmeterol provided less protection than salbutamol. The point of inflection of the curve from baseline moved 1.9 and 3.2 doubling doses, respectively, compared to placebo $(p \leq 0.001)$, and the provocative concentration of methacholine required to produce a $20 \%$ fall in FEV1 (PC20) increased 1.6 and 3.1 doubling doses, respectively $(p \leq 0.001)$. The slope of the DRC was increased slightly by both $\beta$-agonists compared to placebo (log slope 3.11, 3.06 and 2.77 for salmeterol, salbutamol and placebo, respectively). This effect of regular salmeterol on slope was more marked in subjects with lower baseline FEV1. Maximal response plateaus did not differ between the three treatments.

These results suggest that regular use either of short- or long-acting $\beta$-agonists could increase the risk of a more precipitous asthma episode associated with "breakthrough" bronchoconstrictor responses, particularly in those with more severe initial airflow obstruction, if subjects are exposed to a sufficiently potent stimulus.
\end{abstract}

Eur Respir J 1997; 10: 330-336.

Airway hyperresponsiveness and variable airway obstruction are characteristic functional abnormalities in asthma. $[1,2]$. Asthmatics differ from nonasthmatics in the position, slope and maximal response of the doseresponse curve (DRC) to bronchoconstrictor stimuli [3], showing an increased sensitivity to inhaled stimuli, and an increase in maximal constrictor response $[4,5]$. The greater the severity of airway hyperresponsiveness, the greater the level of maximal response [6]. In moderateto-severe asthmatics, a plateau in the constrictor response is usually not measurable, reflecting the potential for "excessive" airway narrowing, which could even lead to fatality $[6,7]$. It has been argued that measuring the sensitivity to bronchoconstrictor agents by determining only the provoking concentration causing a $20 \%$ fall in forced expiratory volume in one second (FEV1) (PC20) does not fully reflect clinically relevant aspects of asthma [8], and that the level of the maximal response may be a stronger predictor of the severity of symptoms.
The Asthma Research Group, Dept of Medicine, St Joseph's Hospital and McMaster University, Hamilton, Ontario, Canada.

Correspondence: M.R. Sears Firestone Regional Chest and Allergy Unit

St Joseph's Hospital

50 Charlton Avenue East

Hamilton

Ontario

Canada

L8N 4A6

Keywords: Airway responsiveness asthma

$\beta$-agonists

dose-response slope

salbutamol

salmeterol

Received: January 11996

Accepted after revision September 15 1996
Short acting $\beta_{2}$-agonists, such as salbutamol, acutely shift the DRC to the right by up to four doubling doses of histamine or methacholine [9], but do not protect against excessive airway narrowing, since there is no change in the level of the plateau [10]. BeL et al. [10] showed that salbutamol may produce a steepening of the slope of the DRC, and suggested that this may allow the possibility of more rapid deterioration should bronchoconstriction break through the $\beta_{2}$-agonist protection following exposure to potent allergens or other provoking agents.

Salmeterol is a topically active long-acting $\beta_{2}$-agonist, with a duration of action of $12 \mathrm{~h}$ compared with 4-6 h for salbutamol $[11,12]$. Chronic use does not appear to lead to tachyphylaxis to its bronchodilator effects [13]. However, CHEUng et al. [14] found that regular treatment with salmeterol in mild asthmatics led to significant tolerance to its bronchoprotective effects against methacholine challenge [14]. A slight reduction in the maximal response to methacholine was observed on 
commencing treatment, but this benefit was lost after several weeks of regular use. Another study showed reduced protection of salmeterol against exercise-induced bronchoconstriction after 4 weeks regular treatment [15].

Limited information exists on the effects of long-acting, $\beta_{2}$-agonists on the DRC to bronchoconstrictor stimuli, with respect to the slope of the response or the level of the maximal constrictor response [14]. Case reports of life-threatening attacks of asthma [16] in young people given salmeterol for previously mild asthma led us to hypothesize that regular use of salmeterol might increase the slope of the DRC when bronchoconstriction occurred as a result of a major provocation. The aim of the present study was to examine the early effects of regular twice daily treatment with salmeterol and salbutamol on the position, slope and maximal airway response of the DRC to methacholine in subjects with asthma.

\section{Methods}

Nineteen adult subjects ( 7 males and 12 females) who met the American Thoracic Society diagnostic criteria for asthma [17] volunteered to participate in the study. Subjects had at least a 1 year history of episodic wheezing and dyspnoea. All but two were atopic, and only one was a current smoker. Eleven subjects were treated with regular daily inhaled corticosteroids and $\beta_{2}$ agonists when needed, while eight used only $\beta_{2}$-agonists when needed. All subjects had a baseline FEV $1>70 \%$ of predicted and $>70 \%$ of vital capacity (VC). Subjects were required to show airway hyperresponsiveness, with a baseline methacholine $\mathrm{PC} 20 \leq 8 \mathrm{mg} \cdot \mathrm{mL}^{-1}$. In addition, subjects were required to show that they could achieve a maximal response plateau on the DRC within a measurable range, with no more than a $60 \%$ fall in FEV 1 from the postsaline value at a methacholine dose $\leq 360$ $\mathrm{mg} \cdot \mathrm{mL}^{-1}$, either untreated or following two puffs of salbutamol, to ensure a plateau would be measurable during the randomized cross-over segments of the study. None had major exacerbations requiring hospitalization or change in asthma medications within the last month, or an upper respiratory infection in the previous 6 weeks. Those whose asthma became unstable due to infections or allergen exposure were subsequently excluded from the study. Subjects were not receiving oral corticosteroids, oral $\beta$-agonists, theophylline, ipratropium bromide, sodium cromoglycate or nedocromil sodium, and had never used long-acting $\beta_{2}$-agonists. Six patients used inhaled corticosteroids. Informed consent was obtained from all subjects prior to participation in the study. The study was approved by the St Joseph's Hospital Research Ethics Committee.

\section{Study design}

Subjects were recruited from out-patient clinics and underwent two screening methacholine challenges. The first challenge was performed at least $6 \mathrm{~h}$ after the last use of short-acting $\beta$-agonist to assess baseline airway responsiveness, and continued until a maximal response plateau was achieved or until a predetermined level of bronchoconstriction occurred (fall in FEV1 $>60 \%$ of postsaline value). The FEV1 did not fall below $1 \mathrm{~L}$ in any subject. A second screening methacholine challenge was performed on a different day commencing $15 \mathrm{~min}$ after two inhalations $(200 \mu \mathrm{g})$ of salbutamol. Subjects who demonstrated a maximal response plateau on one or both of these days were then randomized to receive salbutamol $\left(100 \mu \mathrm{g} \cdot\right.$ puff $\left.^{-1}\right)$, salmeterol $\left(25 \mu \mathrm{g} \cdot\right.$ puff $\left.^{-1}\right)$ and placebo in a double-blind, three-way cross-over design.

Subjects who used inhaled corticosteroids at entry were instructed to continue this medication throughout the entire study at the same dose. All subjects were allowed open label inhaled salbutamol, as needed for symptom relief. Trial medications were taken at a dose of two puffs every $12 \mathrm{~h}$ for 4 days, using a Ventahaler ${ }^{\circledR}$ spacer device. Methacholine challenge was carried out on Day 5, commencing 15 min after treatment with two puffs of the trial medication administered in the laboratory. A typical challenge procedure took 40-45 min, so the final dose of each challenge was inhaled about 1 $\mathrm{h}$ after inhalation of salmeterol, salbutamol or placebo. Treatment periods were separated by a wash-out period of at least 10 days.

\section{Measurements}

Spirometric measurements (FEV1 and VC) were obtained using a dry wedge spirometer (Model 270 wedge spirometer; Med Science, St. Louis, MO, USA) with results displayed on an X-Y recorder (HP 7041A; HewlettPackard; Andover, MA, USA). Baseline FEV1 and VC were recorded as the highest of three reproducible measurements. The degree of bronchodilitation following salbutamol, salmeterol or placebo was determined 15 min after two puffs of the subject's test medication inhaled through a Ventahaler ${ }^{\circledR}$ spacer.

Methacholine challenges were performed according to the protocol of CocKCROFT et al. [18]. Each challenge was preceded by a $15 \mathrm{~min}$ period of rest following inhalation of medication. After inhalation of saline, complete DRC were obtained using doubling concentrations of acetyl- $\beta$-methylcholine chloride dissolved in normal saline $\left(0.03-360 \mathrm{mg} \cdot \mathrm{mL}^{-1}\right)$. The aerosols were generated by a Wright nebulizer (output $0.13 \mathrm{~mL} \cdot \mathrm{min}^{-1}$ ) and inhaled by tidal breathing for 2 min with the nose clipped. FEV1 was measured at 30 and $90 \mathrm{~s}$ after each dose. If the FEV1 was lower at $90 \mathrm{~s}$ than at $30 \mathrm{~s}$, additional measurements were made at $180 \mathrm{~s}$ and every $2 \mathrm{~min}$ thereafter, until the lowest FEV1 was determined. The initial methacholine concentration used was always two concentrations less than the $\mathrm{PC} 20$ determined on the first screening day. Fourfold increments were used until FEV1 fell $\geq 6 \%$, and then twofold increments until FEV1 fell $\geq 15 \%$. Concentration increments of half the doubling dose were then used until a maximal response plateau was demonstrated, or FEV1 fell $>60 \%$ from the postsaline value, or a concentration of $360 \mathrm{mg} \cdot \mathrm{mL}^{-1}$ was given, or increasing asthma symptoms necessitated termination of the test.

\section{Statistical analysis}

The bronchoconstricting effect of each dose of methacholine was expressed as the percentage fall in FEV1 from the postsaline value. FEV1 was plotted against the 
log concentration of methacholine, and the PC20 was calculated by log-linear interpolation between the data points either side of the $20 \%$ fall. A maximal response plateau was considered to be present if two or more FEV 1 measurements fell within $5 \%$ of each other; the mean of these consecutive data points was calculated to determine the level of the maximal response. The slope of the DRC was calculated by linear regression analysis (using the method of least squares) of the data points in the "middle" part of the DRC, including the two data points used in determining the PC20 and all consecutive data points up to the first point of the plateau, or up to the last data point if no plateau was demonstrated. Prior to unblinding of the study, it was noted that in 4 of 70 challenges, FEV1 fell $>20 \%$ during the use of fourfold increments in methacholine concentrations; in these four cases, slope calculations do not include the data point prior to the $20 \%$ fall. The point of inflection of the curve (IC) from baseline was determined by extrapolation of the regression line of the slope back to a zero Y-value. Natural logarithms of slope, PC20 and IC were used in the statistical analysis. The differences in FEV1, IC, PC20, slope and maximal response plateau between and within the three treatment groups were examined using analysis of variance (ANOVA) of repeated measures. The significance of any detected differences was determined using two-sided Student's paired and unpaired t-tests. Comparisons were made between effects of regular salmeterol and placebo, salbutamol and placebo, and salmeterol and salbutamol. The untreated challenge (first screening visit) was also compared with that after 4 days of regular placebo; the effects of single dose salbutamol (second screening visit) were compared with regular salbutamol. A p-value less than 0.05 was considered statistically significant. Data were analysed using the Statistical Package for the Social Sciences (SPSS) for Windows, version 6.0 (SPSS Inc., Chicago, IL, USA).

\section{Results}

\section{Demographic data}

Nineteen subjects were randomized into the study, but data from only 14 subjects ( 6 males and 8 females, mean (SD) age 38 yrs (12)) were analysed. Two subjects did not strictly fulfil entry criteria, one subject developed an upper respiratory infection after randomization, one had unstable asthma due to seasonal allergen exposure, and one had missing data.

Baseline spirometry and DRC data from the two prerandomization visits are presented in table 1 . The mean (SD), FEV1/VC was 75 (7.0) \%, and the mean (SD) degree of reversibility to salbutamol at the second prerandomization visit was 6.2 (3.5) \% increase in FEV1. The mean shift in IC following a single dose of salbutamol was 3.8 doubling doses, and in PC20 3.7 doubling doses, with no change in slope or level of plateau compared with the baseline visit. Subjects had a mean (SD) fall in FEV1 of 4.7 (3.3) \% from baseline after saline inhalation during the first prerandomization challenge. Following 4 days pretreatment, the mean increase in FEV1 from baseline at $15 \mathrm{~min}$ was $7.2(5.1) \%$ after $200 \mu \mathrm{g}$ salbutamol, 2.4 (4.5) \% after $50 \mu \mathrm{g}$ salmeterol $(\mathrm{p}<0.05)$, and $0.25(3.8) \%$ after placebo $(\mathrm{p}<0.001)$. The geometric mean baseline $\mathrm{PC} 20$ in the 14 subjects was 1.82 $\mathrm{mg} \cdot \mathrm{mL}^{-1}$. There were no significant changes in baseline $\mathrm{FEV} 1$ or $\mathrm{VC}$ among the treatment periods.

\section{Airway responsiveness}

Individual methacholine $\mathrm{PC} 20$ results and the IC following each study medication are shown in table 2 , and mean data are shown graphically as complete DRCs in

Table 1. - Demographic and treatment variables, baseline lung function, and features of individual dose-response curves to methacholine at screening visits without pretreatment and 15 min after $200 \mu \mathrm{g}$ salbutamol

\begin{tabular}{|c|c|c|c|c|c|c|c|c|c|c|c|c|}
\hline \multirow[b]{2}{*}{$\begin{array}{l}\text { Ss } \\
\text { No. }\end{array}$} & \multirow[b]{2}{*}{ Sex } & \multirow[b]{2}{*}{$\begin{array}{l}\text { Age } \\
\text { Yrs }\end{array}$} & \multirow[b]{2}{*}{$\begin{array}{c}\text { Steroid } \\
\mu \mathrm{g} \cdot \text { day }^{-1}\end{array}$} & \multirow[b]{2}{*}{$\begin{array}{l}\text { FEV1 } \\
\% \text { pred }\end{array}$} & \multicolumn{4}{|c|}{ Baseline: no medication } & \multicolumn{4}{|c|}{ Baseline: 15 min postsalbutamol } \\
\hline & & & & & $\underset{\mathrm{mg} \cdot \mathrm{mL}^{-1}}{\mathrm{IC}}$ & $\begin{array}{c}\mathrm{PC} 20 \\
\mathrm{mg} \cdot \mathrm{mL}^{-1}\end{array}$ & Slope & $\begin{array}{c}\text { Plateau } \\
\%\end{array}$ & $\underset{\mathrm{mg} \cdot \mathrm{mL}^{-1}}{\mathrm{IC}}$ & $\begin{array}{c}\mathrm{PC}_{20} \\
\mu \mathrm{g} \cdot \mathrm{mL}^{-1}\end{array}$ & Slope & Plateau \\
\hline 1 & M & 30 & 0 & 92 & 0.35 & 0.66 & 32.0 & 45 & 7.45 & 18.60 & 26.6 & 54 \\
\hline 2 & $\mathrm{~F}$ & 38 & 0 & 108 & 0.69 & 2.46 & 15.9 & 35 & 32.80 & 113.40 & 15.6 & NA \\
\hline 3 & $\mathrm{~F}$ & 38 & 0 & 88 & 1.32 & 4.54 & 16.0 & 32 & 6.08 & 29.12 & 12.1 & 26 \\
\hline 4 & M & 20 & 0 & 80 & 1.12 & 3.70 & 15.9 & 28 & 44.97 & 115.90 & 22.1 & 32 \\
\hline 5 & $\mathrm{~F}$ & 37 & 0 & 96 & 0.48 & 2.30 & 15.4 & 46 & 7.05 & 17.99 & 21.4 & 34 \\
\hline 6 & M & 21 & 0 & 86 & 1.20 & 2.07 & 36.5 & 46 & 81.50 & 97.20 & 115.0 & 53 \\
\hline 7 & M & 46 & 0 & 80 & 1.09 & 2.13 & 28.7 & 52 & 7.79 & 20.20 & 21.6 & 53 \\
\hline 8 & $\mathrm{~F}$ & 20 & 0 & 89 & 0.27 & 0.77 & 18.8 & 27 & 12.60 & 40.85 & 11.6 & 30 \\
\hline 9 & M & 42 & 1000 & 96 & 0.15 & 0.42 & 19.1 & 38 & 1.68 & 3.30 & 21.7 & NA \\
\hline 10 & $\mathrm{~F}$ & 60 & 800 & 103 & 0.33 & 1.86 & 11.7 & 34 & 5.85 & 24.80 & 13.5 & 28 \\
\hline 11 & M & 53 & 400 & 88 & 0.23 & 1.66 & 14.8 & NA & 44.80 & 81.90 & 29.8 & 23 \\
\hline 12 & $\mathrm{~F}$ & 43 & 500 & 88 & 0.94 & 2.71 & 19.2 & 51 & 3.98 & 9.58 & 22.8 & 43 \\
\hline 13 & $\mathrm{~F}$ & 37 & 200 & 104 & 1.46 & 3.03 & 36.8 & NA & 1.93 & 5.04 & 19.7 & 50 \\
\hline 14 & $\mathrm{~F}$ & 44 & 800 & 88 & 0.52 & 1.92 & 17.6 & 43 & 0.50 & 4.24 & 9.3 & 26 \\
\hline Mean & & 38 & $\begin{array}{r}617 \\
(n=6)\end{array}$ & 91 & $0.58^{\ddagger}$ & $1.82^{\ddagger}$ & 20.0 & 40 & $8.2^{\ddagger}$ & $23.3^{\ddagger}$ & 20.6 & 38 \\
\hline
\end{tabular}

\$: geometric mean. Ss: subjects; M: male; F: female; FEV1: forced expiratory volume in one second; \% pred: percentage of predicted value; IC: point of inflection of the dose-response curve; slope: slope expressed as percentage fall of FEV1 (from post-normal saline baseline) divided by $\log (\mathrm{n}) \mathrm{mg} \cdot \mathrm{mL}^{-1}$; PC20: provocative concentration causing a $20 \%$ fall in FEV1; NA: maximal response plateau not achieved. 
Table 2. - Features of individual dose-response curves to methacholine after 4 days pretreatment with salmeterol, salbutamol and placebo

\begin{tabular}{|c|c|c|c|c|c|c|c|c|c|c|c|c|}
\hline \multirow{2}{*}{$\begin{array}{l}\text { Ss } \\
\text { No. }\end{array}$} & \multicolumn{4}{|c|}{ Placebo } & \multicolumn{4}{|c|}{ Salmeterol } & \multicolumn{4}{|c|}{ Salbutamol } \\
\hline & $\frac{\mathrm{IC}}{\mathrm{mg} \cdot \mathrm{mL}^{-1}}$ & $\begin{array}{c}\mathrm{PC} 20 \\
\mathrm{mg} \cdot \mathrm{mL}^{-1}\end{array}$ & $\begin{array}{l}\log \\
\text { slope }^{\#}\end{array}$ & $\begin{array}{c}\text { Plateau } \\
\%\end{array}$ & $\begin{array}{c}\mathrm{IC} \\
\mathrm{mg} \cdot \mathrm{mL}^{-1}\end{array}$ & $\begin{array}{c}\mathrm{PC} 20 \\
\mathrm{mg} \cdot \mathrm{mL}^{-1}\end{array}$ & $\begin{array}{l}\log \\
\text { slope }^{\#}\end{array}$ & $\begin{array}{c}\text { Plateau } \\
\%\end{array}$ & $\begin{array}{c}\mathrm{IC} \\
\mathrm{mg} \cdot \mathrm{mL}^{-1}\end{array}$ & $\begin{array}{c}\mathrm{PC}_{20} \\
\mathrm{mg} \cdot \mathrm{mL}^{-1}\end{array}$ & $\begin{array}{l}\text { Log } \\
\text { slope }^{\#}\end{array}$ & $\begin{array}{c}\text { Plateau } \\
\%\end{array}$ \\
\hline 1 & 0.45 & 1.15 & 3.22 & NA & 3.70 & 8.68 & 3.20 & NA & 5.99 & 18.30 & 2.99 & NA \\
\hline 2 & 0.97 & 3.48 & 2.82 & 31 & 4.80 & 19.00 & 2.70 & 36 & 15.50 & 37.50 & 2.95 & 40 \\
\hline 3 & 1.83 & 5.12 & 2.98 & 36 & 8.28 & 18.56 & 3.21 & 34 & 16.53 & 37.29 & 3.19 & 32 \\
\hline 4 & 0.69 & 3.80 & 2.37 & 30 & 3.99 & 13.60 & 2.67 & 41 & 13.10 & 33.20 & 3.03 & 44 \\
\hline 5 & 0.36 & 1.16 & 2.88 & 43 & 2.88 & 5.17 & 3.51 & 41 & 2.21 & 7.56 & 2.87 & 38 \\
\hline 6 & 0.89 & 3.67 & 2.78 & 44 & 4.36 & 10.58 & 3.10 & 36 & 13.62 & 34.50 & 4.19 & NA \\
\hline 7 & 2.26 & 4.90 & 3.24 & 50 & 2.28 & 3.75 & 3.69 & 51 & 3.95 & 8.96 & 3.13 & 57 \\
\hline 8 & 0.94 & 1.08 & 1.64 & 22 & 0.87 & 7.49 & 2.16 & 22 & 11.17 & 23.88 & 2.72 & 22 \\
\hline 9 & 0.20 & 0.61 & 2.90 & 54 & 0.50 & 1.47 & 2.91 & 49 & 2.43 & 5.77 & 3.19 & 56 \\
\hline 10 & 0.79 & 1.93 & 3.06 & 35 & 2.24 & 6.24 & 3.01 & 32 & 4.81 & 17.40 & 2.80 & 33 \\
\hline 11 & 0.62 & 2.80 & 2.59 & 40 & 35.00 & 50.00 & 4.04 & 33 & 28.50 & 58.90 & 3.28 & 42 \\
\hline 12 & 1.44 & 7.04 & 2.56 & 49 & 1.88 & 4.48 & 2.76 & 39 & 1.08 & 17.90 & 2.85 & 54 \\
\hline 13 & 2.23 & 4.67 & 3.29 & 44 & 2.15 & 3.18 & 3.64 & NA & 9.30 & 22.47 & 3.10 & 51 \\
\hline 14 & 0.10 & 0.78 & 2.41 & 43 & 0.61 & 1.72 & 2.96 & 44 & 2.45 & 10.93 & 2.61 & 33 \\
\hline \multicolumn{13}{|l|}{ Mean } \\
\hline Salbutamol p.r.n & $n 0.88$ & 2.53 & 2.74 & 36 & 3.32 & 9.49 & 3.03 & 38 & 8.5 & 21.5 & 3.13 & 39 \\
\hline Steroid group & 0.55 & 2.09 & 2.80 & 44 & 2.14 & 4.71 & 3.22 & 39 & 4.48 & 17.3 & 2.97 & 45 \\
\hline Overall mean & 0.72 & 2.34 & 2.77 & 40 & 2.75 & 7.03 & 3.11 & 38 & 6.45 & 19.6 & 3.06 & 42 \\
\hline
\end{tabular}

\#: natural logarithm of slope expressed as fall in $\mathrm{FEV}_{1}$ (\% of predicted) divided by log (n) $\mathrm{mg} \cdot \mathrm{mL}^{-1}$. For definitions see legend to table 1.

figure 1 . There were no statistically significant within treatment differences in mean PC20 and IC between the subjects using or not using inhaled corticosteroids, and so data from all 14 subjects were combined for analyses.

The inflection of the methacholine DRC was significantly shifted to the right by regular salmeterol $(\mathrm{p}=0.001$ relative to regular placebo) and regular salbutamol $(\mathrm{p}<0.001$ relative to placebo), but salbutamol shifted the curve further than did salmeterol $(\mathrm{p}<0.005)$. After pretreatment with salmeterol, geometric mean PC20 increased 1.6 doubling doses over placebo $(p=0.001)$, while salbutamol increased $\mathrm{PC} 20$ by 3.1 doubling doses $(\mathrm{p}<0.001)$. Hence, protection against methacholineinduced bronchoconstriction after 4 days of twice daily

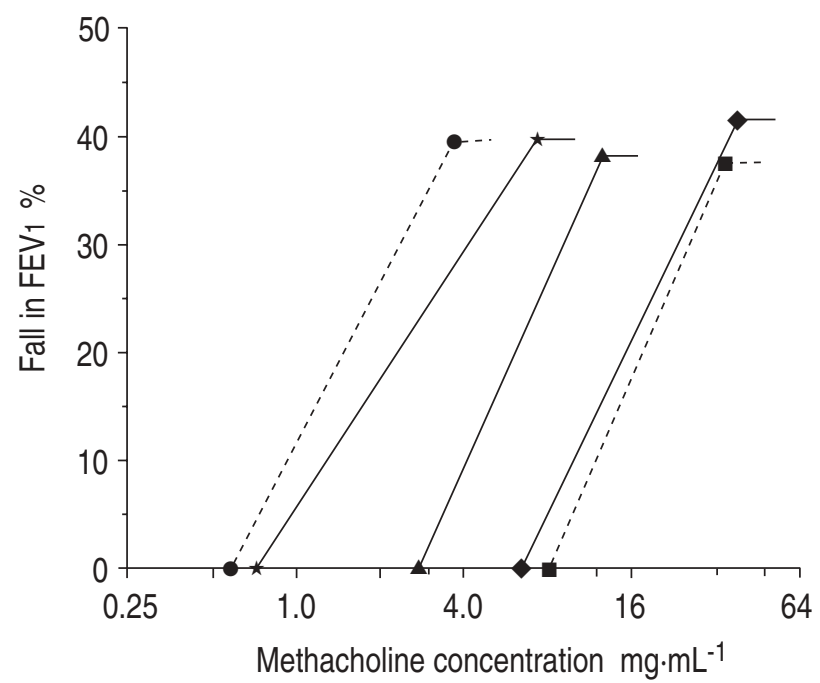

Fig. 1. - Mean dose-response curves for each treatment period (percentage fall of FEV1 from postsaline FEV1), constructed from mean inflection points, slopes and plateaus following salmeterol, salbutamol and placebo. $\boldsymbol{O}$ : prestudy baseline; $\mathbf{\square}$ : prestudy salbutamol; $\boldsymbol{\Lambda}$ : salmeterol; $\diamond$ : salbutamol: $\star$ : placebo. FEV1: forced expiratory volume in one second. salbutamol was significantly greater than after 4 days of twice daily salmeterol $(\mathrm{p}<0.001)$. There were no significant correlations between the magnitude of the change in $\mathrm{PC}_{20}$ and baseline spirometry or the degree of bronchodilatation occurring following study medications before challenge testing.

There were no significant differences between the response to challenge following 4 days placebo and the untreated baseline response, nor between the responses to challenge following single dose salbutamol and that after 4 days regular treatment (fig. 1).

\section{Maximal airway narrowing}

The level of maximal airway narrowing after inhaled methacholine was expressed as the mean percentage fall in FEV1 from the postsaline value to the plateau (table 2). A plateau was obtained on all but five occasions postrandomization. The mean (SD) plateau levels of FEV1 were a fall of 38 (8) \% for salmeterol, 42 (11) \% for salbutamol and 40 (9) \% following placebo. These were not significantly different to each other, or to the prerandomization measurements.

\section{Slope of the dose response curve}

DRC slopes were log transformed prior to analysis. Individual and mean values following each treatment are shown in table 2. The mean slope of the DRC was significantly increased by 4 days treatment either with salmeterol $(\mathrm{p}<0.01)$ or salbutamol $(\mathrm{p}<0.05)$ compared with placebo. There were no significant differences in mean slope between salmeterol and salbutamol treatments. The change in slope following each medication did not differ significantly between those subjects using 


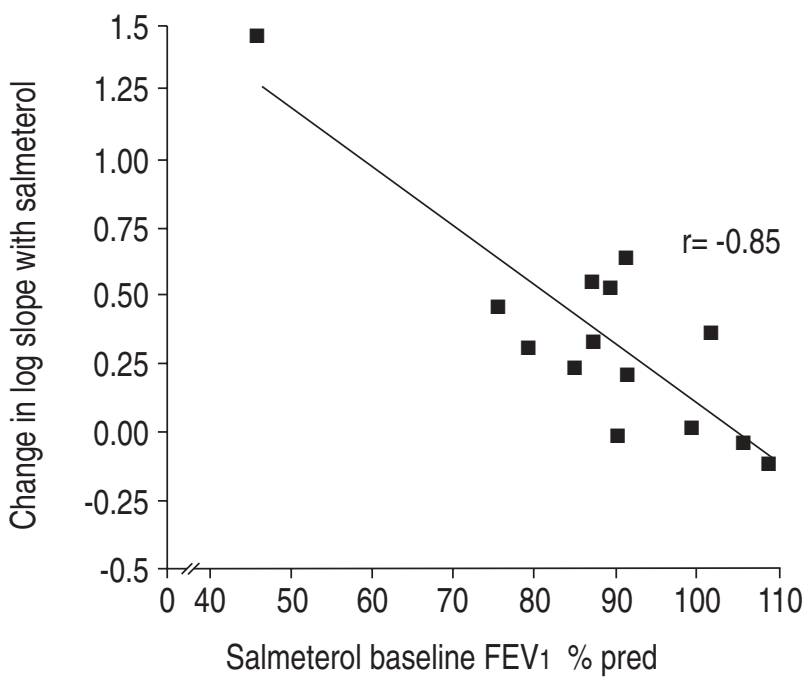

Fig. 2. - Negative correlation between baseline FEV1 obtained on the day of test and change in slope (log) of DRC with salmeterol relative to placebo $(\mathrm{r}=-0.85 ; \mathrm{p}<0.001)$. If the outlying data point is removed, the correlation remains significant $(r=-0.59 ; p<0.03)$. FEV 1 : forced expiratory volume in one second; DRC: dose response curve.

regular inhaled corticosteroids and those using only salbutamol for symptom control.

Pearson correlation coefficients (r) were calculated to determine the relationships between the increase in the slope of the DRC (relative to placebo) after each study medication, and other outcome measures. The increase in slope of the DRC following treatment with salmeterol correlated negatively with the baseline FEV1 obtained on the day of the test $(\mathrm{r}=-0.85 ; \mathrm{p}<0.001)$ (fig. 2$)$, as well as the initial screening FEV1 $(\mathrm{r}=-0.70 ; \mathrm{p}<0.01)$. Therefore, subjects with lower baseline pulmonary function had a greater steepening of the slope of the DRC. A trend towards this effect was also seen with salbutamol, but did not achieve significance $(\mathrm{r}=-0.48 ; \mathrm{p}=0.084)$.

\section{Discussion}

Both salmeterol and salbutamol produce bronchodilation and protect, to a degree, against methacholine-induced bronchoconstriction. However, neither salmeterol nor salbutamol reduce the level of maximal airway narrowing. Furthermore, both medications used twice daily for 4 days slightly increased the slope of the methacholine DRC compared to placebo. These results raise further questions regarding the use of regular treatment with $\beta_{2}$-agonists, as single dose (p.r.n. use) seems as effective in providing bronchoprotection, whilst regular use might increase the risk of more severe breakthrough bronchoconstriction under some circumstances.

BEL et al. [10] have previously demonstrated that salbutamol increased the slope of the methacholine DRC in asthma [10]. This current study supports the findings with salbutamol and also reveals a similar increase in slope after only 4 days regular use of salmeterol. The potential for more rapid breakthrough bronchoconstriction together with the lack of reduction of maximal airway narrowing provides one possible explanatory mechanism for recent case reports of sudden deterioration or deaths in asthmatics who were using salmeterol $[16,19]$.
A new finding from the present study was the negative correlation between the increase in slope of the DRC after pretreatment with salmeterol and the baseline spirometry. The results suggest that asthmatics with lower baseline pulmonary function, who should theoretically benefit more from the bronchodilator effects of salmeterol, also develop a greater increase in slope of the DRC. These results were found despite the recruitment of asthmatics with relatively mild degrees of airflow obstruction (mean $\mathrm{FEV} 1 / \mathrm{VC} 75 \%$ ), and were not modified by concomitant use of inhaled corticosteroid.

There is a growing body of evidence that regular therapy with short-acting $\beta_{2}$-agonists, especially the more potent agents, may be deleterious [20], although some argue against this position [21, 22]. Regular use of short-acting $\beta_{2}$-agonists has been associated with changes in airway responsiveness, including a rebound increase after cessation of therapy [23]. Tolerance to the protective effects of short-acting $\beta_{2}$-agonists against methacholine- and allergen-induced bronchoconstriction has been shown after chronic use [24, 25]. Some clinical trials have found a decrease in pulmonary function and asthma control, and an increase in bronchial hyperresponsiveness in asthmatics using regular treatment with these medications $[26,27]$. These results, and epidemiological evidence associating asthma mortality with more frequent use of $\beta_{2}$-agonists, have brought into question the safety of regular use of short-acting $\beta_{2}$-agonists [20].

In the present study, PC 20 was moved into the "normal" range of airway responsiveness by salbutamol and into the "mildly increased" range of airway responsiveness by salmeterol. Despite this reduction in airway reactivity as conventionally measured, there was no reduction in the maximal response plateau. Untreated subjects with normal or only mildly increased airway responsiveness at baseline generally have a dose-response plateau at much lower levels of airway narrowing [6, 7]. Maximal airway narrowing is thought to be determined by smooth muscle contractility and thickness of the airway wall, which $\beta$-agonists do not appear to affect. Asthma treatment might be more effective if directed at limiting or preventing excessive airway narrowing [28].

Overall, the subjects showed relatively small increases in FEV1 with study medications, since the subjects had mild asthma and, therefore, near normal values at baseline. Nevertheless, salbutamol produced significantly greater bronchodilation than salmeterol. Since baseline FEV1 measurements were made 15 min after giving the medication, this difference in bronchodilator effect is likely to be due to the slower onset of action of salmeterol compared to salbutamol (17.6 and $0.8 \mathrm{~min}$, respectively) [29]. However, the slower onset of effect is unlikely to be a consideration with respect to the significantly greater protection given by salbutamol against methacholine-induced bronchoconstriction compared to salmeterol. Both medications were given regularly for four consecutive days prior to measuring airway responsiveness. Measurements were made no later than $12 \mathrm{~h}$ after the previous dose, and so the bronchoprotective activity of salmeterol should still be present at the time of testing [30, 31]. Furthermore, the duration of the mechacholine challenge was on average $45 \mathrm{~min}$, so that the time of the final concentration or maximal challenge 
was about $60 \mathrm{~min}$ after dosing, at which time salmeterol should be exerting its maximal effect. Therefore, in mild asthmatics, salmeterol in usual twice daily dosage appears to provide less protection than salbutamol against methacholine-induced bronchoconstriction. As salbutamol was also given only twice daily, its bronchoprotective effect may have been closer to that observed after once only (p.r.n.) use than to that occurring when salbutamol is used three or four times daily.

Regular use of salmeterol leads to tolerance with respect to protection against bronchoconstrictor stimuli, such as inhaled methacholine [14], or exercise [15], but has not been shown to have a deleterious effect on asthma control. BHAGAT et al. [32] have recently shown that the degree of bronchoprotection provided by salmeterol declines quickly, in that the shift in PC20 decreased from 3.3 doubling doses to only 1.5 doubling doses within 4 days of commencing therapy. They also found that a supplementary dose of salbutamol, $200 \mu \mathrm{g}$, used as "rescue therapy" during salmeterol treatment gave substantially reduced protection (from 3.7 to 1.9 doubling dose shift in PC20). These effects occur both in subjects treated with inhaled corticosteroid and those using $\beta$-agonists only $[33,34]$. Our results suggest that use of a single (p.r.n.) dose of salbutamol provides more effective bronchoprotection than regular use of salmeterol. Hence, it may be more effective to use an occasional dose of shortacting $\beta$-agonist if effective bronchoprotection is required in a particular circumstance, rather than to rely on twice daily use of a long-acting $\beta$-agonist.

A postmarketing study in the UK compared the safety of regular use of salmeterol and salbutamol in asthma. The odds ratio for death in the salmeterol treated subjects was 3.0, although the small number of deaths in the study (14 among over 25,000 subjects) meant this finding was statistically insignificant (95\% confidence interval 0.7-20.0) [35]. Case reports of sudden and unexpected deterioration of asthma in subjects taking regular salmeterol, who were previously regarded as not having particularly troublesome asthma [16], and isolated case reports of deaths occurring while using salmeterol [19] are difficult to interpret. Thus, the safety of regular use of long-acting $\beta$-agonists remains uncertain. Our findings indicate the need for continued surveillance of the safety of regular use of these medications, particularly in those with more troublesome asthma.

In summary, salmeterol inhalation following regular twice daily use at recommended dosage gave less protection against methacholine challenge than salbutamol, and was associated with a slight increase in the slope of the bronchoconstrictor dose-response curve to methacholine, more so in those with reduced baseline forced expiratory volume in one second. These findings, although small in magnitude, add to concerns about the possibility that regular long-acting, as well as short-acting, $\beta$-agonist may have deleterious effects in some asthmatics.

\section{References}

1. Hargreave FE, Dolovich J, O'Byrne PM, Ramsdale EH, Daniel EE. The origin of airway hyperresponsiveness. J Allergy Clin Immunol 1986; 78: 825-832.

2. Holgate ST, Beasley R, Twentyman OP. The pathogenesis and significance of bronchial hyperresponsiveness in airways disease. Clin Sci 1987; 73: 561-572.

3. Woolcock AJ, Salome CM, Yan K. The shape of the dose-response curve to histamine in asthmatic and normal subjects. Am Rev Respir Dis 1984; 130: 71-75.

4. Sterk PJ, Bel EH. The shape of the dose-response curve to bronchoconstrictor agents in asthma and in chronic obstructive pulmonary disease. Am Rev Respir Dis 1991; 143: 1433-1437.

5. Cockcroft DW. Nonallergic airway responsiveness. $J$ Allergy Clin Immunol 1988; 81: 111-119.

6. Sterk PJ, Timmers MC, Dijkman JH. Maximal airway narrowing in humans in vivo: histamine compared with methacholine. Am Rev Respir Dis 1986; 134: 714-718.

7. Sterk PJ, Daniel EE, Zamel N, Hargreave FE. Limited bronchoconstriction to methacholine using partial flowvolume curves in nonasthmatic subjects. Am Rev Respir Dis 1985; 132: 272-277.

8. Sterk PJ. The determinants of the severity of acute airway narrowing in asthma and COPD. Respir Med 1992; 86: 391-396.

9. Tattersfield AE. Effect of beta-agonists and anticholinergic drugs on bronchial reactivity. Am Rev Respir Dis 1987; 136(Suppl. 4): S64-S68.

10. Bel EH, Zwinderman AH, Timmers MC, Dijkman JH, Sterk PJ. The protective effect of a beta ${ }_{2}$-agonist against excessive airway narrowing in response to bronchoconstrictor stimuli in asthma and chronic obstructive lung disease. Thorax 1991; 46: 9-14.

11. Ullman A, Svedmyr N. Salmeterol, a new long-acting

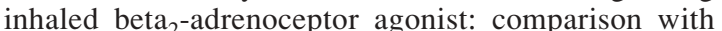
salbutamol in adult asthmatic patients. Thorax 1988; 43: 674-678.

12. Ball DI, Brittain RT, Coleman RA, et al. Salmeterol, a novel, long-acting beta ${ }_{2}$-adrenoceptor agonist: characterization of pharmacological activity in vitro and in vivo. Br J Pharmacol 1991; 104: 665-671.

13. Ullman A, Hedner J, Svedmyr N. Inhaled salmeterol and salbutamol in asthmatic patients: an evaluation of asthma symptoms and the possible development of tachyphylaxis. Am Rev Respir Dis 1990; 142: 571-575.

14. Cheung D, Timmers MC, Zwinderman AH, Bel EH, Dijkman JH, Sterk PJ. Long-term effects of a long-acting $\beta_{2}$-adrenoceptor agonist, salmeterol, on airway hyperresponsiveness in patients with mild asthma. $N$ Engl $J$ Med 1992; 327: 1198-1203.

15. Ramage L, Lipworth BJ, Ingram CG, Cree IA, Dhillon DP. Reduced protection against exercise-induced bronchoconstriction after chronic dosing with salmeterol. Respir Med 1992; 88: 363-368.

16. Clark CE, Ferguson AD, Siddorn JA. Respiratory arrests in young asthmatics on salmeterol. Respir Med 1993; 87: 227-228.

17. Dantzker DR, Pingleton SK, Pierce JA, et al. Standards for the diagnosis and care of patients with chronic obstructive pulmonary disease (COPD) and asthma. Am Rev Respir Dis 1987; 136: 225-244.

18. Cockcroft DW, Killian DN, Mellon JA, Hargreave FE. Bronchial reactivity to inhaled histamine: a method and clinical survey. Clin Allergy 1977; 7: 235-243.

19. Finkelstein FN. Risks of salmeterol? N Engl J Med 1994; 331: 1314.

20. Sears MR, Taylor DR. The $\beta_{2}$-agonist controversy. Observations, explanations and relationship to asthma epidemiology. Drug Safety 1994; 11: 259-283.

21. Ziment I. Beta ${ }_{2}$-agonists and their antagonists. Chest 1994; 106: 329-331. 
22. McFadden ER. Perspectives in $\beta_{2}$-agonist therapy: Vox clamantis in deserto vel lux in tenebris? J Allergy Clin Immunol 1995; 95: 641-651.

23. Vathenen AS, Higgins BG, Knox AJ, Britton JR, Tattersfield AE. Rebound increase in bronchial responsiveness after treatment with inhaled terbutaline. Lancet 1988; i: 554-558.

24. O'Connor BJ, Aikman SL, Barnes PJ. Tolerance to bronchodilator effects of inhaled $\beta_{2}$-agonists in asthma. $N$ Engl J Med 1992; 327: 1204-1208.

25. Cockcroft DW, McPaarland CP, Britto SA, Swystun VA, Rutherford BC. Regular inhaled salbutamol and airway responsiveness to allergen. Lancet 1993; 342: 833-837.

26. Sears MR, Taylor DR, Print CG, et al. Regular inhaled $\beta$-agonist treatment in bronchial asthma. Lancet 1990; 336: 1391-1396.

27. van Schayck CP, Graafsma SJ, Visch MB, Dompeling E, van Weel C, van Herwaarden CLA. Increased bronchial hyperresponsiveness after inhaling salbutamol during 1 year is not caused by subsensitization to salbutamol. J Allergy Clin Immunol 1990; 86: 793-800.

28. Macklem PT. The clinical relevance of respiratory muscle research. Am Rev Respir Dis 1986; 134: 812815.

29. Ullman A, Bergendal A, Linden A, et al. Onset of action and duration of effect of formoterol and salmeterol compared to salbutamol in isolated guinea-pig trachea with or without epithelium. Allergy 1992; 47: 384-387.

30. Derom EY, Pauwels RA, Van der Straeten ME. The effect of inhaled salmeterol on methacholine responsiveness in subjects with asthma up to 12 hours. $J$ Allergy Clin Immunol 1992; 89: 811-815.

31. Booth H, Fishwick K, Harkawat R, Devereux G, Hendrick DJ, Walters EH. Changes in methacholineinduced bronchoconstriction with the long-acting beta ${ }_{2}$ agonist salmeterol in mild to moderate asthmatic patients. Thorax 1993; 48: 1121-1124.

32. Bhagat R, Kalra S, Swystun VA, Cockcroft DW. Rapid onset of tolerance to the bronchoprotective effect of salmeterol. Chest 1995; 108: 1235-1239.

33. Kalra S, Swystun VA, Bhagat R, Cockcroft DW. Inhaled corticosteroids do not prevent the development of tolerance to the bronchoprotective effect of salmeterol. Chest 1996; 109: 953-956.

34. Sears MR. Long-acting $\beta$-agonists, tachyphylaxis and corticosteroids. Chest 1996; 109: 862-864.

35. Castle W, Fuller R, Hall J, Palmer J. Serevent nationwide surveillance study: comparison of salmeterol with salbutamol in asthmatic patients who require regular bronchodilator treatment. Br Med J 1993; 306: 10341037. 